\title{
Advanced Methods of Pharmacokinetic and Pharmacodynamic Systems Analysis
}




\title{
Advanced Methods of Pharmacokinetic and Pharmacodynamic Systems Analysis
}

\author{
Edited by \\ David Z. D'Argenio \\ University of Southern California \\ Los Angeles. California
}

Springer Science+Business Media, LLC 


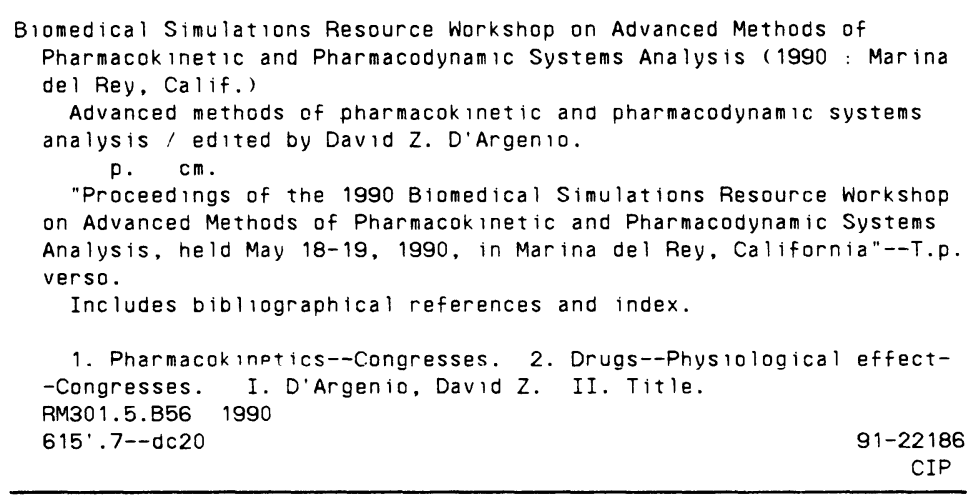

Proceedings of the 1990 Biomedical Simulations Resource Workshop on Advanced Methods of Pharmacokinetic and Pharmacodynamic Systems Analysis, held May 18-19, 1990, in Marina del Rey, California

ISBN 978-1-4757-9023-8

ISBN 978-1-4757-9021-4 (eBook)

DOI 10.1007/978-1-4757-9021-4

\section{(C) Springer Science+Business Media New York 1991 \\ Originally published by Plenum Press, New York in 1991 \\ Softcover reprint of the hardcover 1st edition 1991}

\section{All rights reserved}

No part of this book may be reproduced, stored in a retrieval system, or transmitted in any form or by any means, electronic, mechanical, photocopying, microfilming, recording, or otherwise, without written permission from the Publisher 


\section{PREFACE}

This volume records the proceedings of the Workshop on Advanced Methods of Pharmacokinetic and Pharmacodynamic Systems Analysis, organized by the Biomedical Simulations Resource in May 1990. The meeting brought together over 120 investigators from a number of disciplines, including clinical pharmacology, clinical pharmacy, pharmaceutical science, biomathematics, statistics and biomedical engineering with the purpose of providing a high-level forum to facilitate the exchange of ideas between basic and clinical research scientists, experimentalists and modelers working on problems in pharmacokinetics and pharmacodynamics.

It has been my experience that in many areas of biomedical research, when a meeting of this type is held, the general attitude of those experimentalists willing to attend is one of extreme skepticism: as a group they feel that mathematical modeling has little to offer them in furthering their understanding of the particular biological processes they are studying. This is certainly not the prevailing view when the topic is pharmacokinetics and drug response. Quite the contrary, the use of mathematical modeling and associated data analysis and computational methods has been a central feature of pharmacokinetics almost from its beginnings. In fact, the field has borrowed techniques of modeling from other disciplines including applied mathematics, statistics and engineering, in an effort to better describe and understand the processes of drug disposition and drug response. This transfer of intellectual technology, however, has and continues to be done with a keen power of discrimination on the part of basic and clinical scientists in the field. What I have found to be especially significant, moreover, is that the general area of pharmacokinetics has also provided a return benefit to those disciplines from which it has borrowed, in that the difficult problems in pharmacokinetics have provided fertile ground for the development of new approaches and significant extensions to existing techniques of mathematical modeling, data analysis, and scientific computing.

The contributors to this volume are representative of those investigators who by addressing fundamentally important basic and clinical research problems have also provided a stimulus for development of new methodologies of modeling and data analysis in pharmacokinetics and pharmacodynamics. Other contributors are indicative of the biomathematicians, engineers and statisticians who have accepted the challenge of developing these new modeling, data analysis and computational techniques.

The book itself is divided into four sections. The first involves contributions on the physiological and biochemical basis of pharmacokinetics, including chapters on the mechanisms of oral drug absorbtion, reversible metabolic processes, novel drug delivery systems for anticancer and antiviral agents, and the significance of blood sampling site in pharmacokinetic studies. The second section addresses mea- 
surement and modeling issues in pharmacodynamics as they relate to the study of corticosteroids, intravenous anesthetics and cardioactive drugs, as well as physiological approaches to pharmacodynamic modeling. Section three on pharmacometrics includes chapters on residence time distributions, estimation with model uncertainty, population analysis with intraindividual variability, and optimal design of dosage regimens. The last section addresses problems of measurement, control and drug delivery in pharmacotherapeutics, with chapters on fiber optic sensors for detecting general anesthetics, individualizing drug therapy in renal transplant and pediatric cancer patients, and drug delivery via a computer controlled infusion pump.

I wish to thank all the authors for their excellent contributions to this volume and for their generous and enthusiastic participation in the 1990 BMSR Workshop. It is with great pleasure that I acknowledge the many contributions of Mrs. Gabriele Larmon in both the efficient organization of the Workshop and in the professional preparation of this volume. Also, I would like to thank Nicolas Rouquette for his TEXnical expertise. Finally, I wish to acknowledge the support of the Biomedical Research Technology Program of the National Center for Research Resources of NIH for its support of the BMSR and its activities. 


\section{CONTENTS}

\section{PHARMACOKINETICS: PHYSIOLOGICAL AND BIOCHEMICAL BASIS}

Predicting Oral Drug Absorption in Humans: A Macroscopic Mass Balance

Approach for Passive and Carrier-Mediated Compounds ............. 3

Doo-Man Oh, Patrick J. Sinko and Gordon L. Amidon

Pharmacokinetics of Linear Reversible Metabolic Systems ...

Haiyung Cheng and William J. Jusko

Pharmacokinetic Models for Anticancer and Antiviral Drugs

following Administration as Novel Drug Delivery Systems

James M. Gallo

The Significance of Marked "Universal" Dependence of Drug Concentration on Blood Sampling Site in Pharmacokinetics and Pharmacodynamics ... 37

Win L. Chiou

\section{PHARMACODYNAMICS: MEASUREMENTS AND MODELS}

Physiological Alternatives to the Effect Compartment Model ............... 55

Nicholas H.G. Holford

Pharmacokinetics/Dynamics of Corticosteroids ...................... 61

William J. Jusko

Variability in Human Cardiovascular Pharmacodynamics ................. 69

Darrell R. Abernethy

Pharmacodynamic Modeling of Thiopental Depth of Anesthesia ............ 79

Donald R. Stanski 


\section{PHARMACOMETRICS: MODELING, ESTIMATION AND CONTROL}

Residence Time Distributions in Pharmacokinetics:

Behavioral and Structural Models .......................... 89

Michael Weiss

Pharmacokinetic Parameter Estimation with Stochastic Dynamic Models 103

David Z. D'Argenio and Ruomei Zhang

Relationships between Intra- or Interindividual Variability and Biological

Covariates: Application to Zidovudine Pharmacokinetics

France Mentré and Alain Mallet

On the Single-Point, Single-Dose Problem

George D. Swanson

Application of Stochastic Control Theory

to Optimal Design of Dosage Regimens

Alan Schumitzky

\section{PHARMACOTHERAPEUTICS: MEASUREMENT, CONTROL AND DELIVERY}

Development of a Fiber Optic Sensor for Detection of General Anesthetics and Other Small Organic Molecules

Sabina Merlo, Paul Yager and Lloyd W. Burgess

A Bayesian Kinetic Control Strategy for Cyclosporin in Renal Transplantation . 171

Brian Whiting, Alison A. Niven, Andrew W. Kelman, Alison H. Thomson, Janet Anderson, Angela Munday, and J. Douglas Briggs

Targeted Systemic Exposure for Pediatric Cancer Therapy

John H. Rodman and William E. Evans

Targeting the Effect Site With a Computer Controlled Infusion Pump 185

Steven L. Shafer

Contributors

Participants

Subject Index 